Supporting Information for

\title{
Backbone-Degradable Vinyl Acetate Latex: Coatings for Single-Use Paper Products
}

Matthew C. D. Carter ${ }^{1 *}$, Andrew Hej1 ${ }^{2}$, Samantha Woodfin ${ }^{2}$, Brian Einsla, ${ }^{2}$ Miroslav Janco ${ }^{1}$, Jim DeFelippis $^{1}$, and Richard J. Cooper ${ }^{1}$, and Ralph C. Even ${ }^{1}$

${ }^{1}$ Core Research \& Development and ${ }^{2}$ Dow Coating Materials, The Dow Chemical Company, 400 Arcola Road, Collegeville, Pennsylvania 19426, USA.

*E-mail: mccarter1@dow.com 


\section{Materials and Methods}

Materials. Vinyl acetate (VA, 99\%), ACRYSOL ${ }^{\text {TM }}$ ASE-60 Thickener, and TERGITOL ${ }^{\text {TM }}$ 15-S40 Surfactant (70 wt\% in water) were obtained from Dow (Midland, MI). 2-Methylene-1,3dioxepane (MDO) was obtained from Wacker Chemie (Adrian, MI). Sodium lauryl ether sulfonate (SLES, $31 \mathrm{wt} \%$ in water, tradename Disponil Fes-32) was obtained from BASF (Florham Park, NJ). 2-Acrylamido-2-methyl-1-propanesulfonic acid sodium salt solution (Na-AMPS, $50 \mathrm{wt} \%$ in water), ammonium persulfate (APS, 98\%), tert-butyl hydroperoxide ( $t$-BHP, $70 \mathrm{wt} \%$ in water), iron (II) sulfate heptahydrate (>99\%), ethylenediaminetetraacetic acid (EDTA, $>98.5 \%), N, N$ dimethylacetamide (HPLC grade), and deuterated $\mathrm{CDCl}_{3}(99.9 \%)$ were obtained from SigmaAldrich (Milwaukee, WI). Bruggolite FF6 M reducing agent was obtained from Brüggemann (Newtown Square, PA). Spectra/Por Float-A-Lyzer G2 dialysis membranes (MWCO = 100-500 Da), phosphate buffered saline 10X concentrate (PBS), sodium bicarbonate buffer, and ammonium hydroxide (28.0-30.0 wt\%) were obtained from Fisher Scientific (Allentown, PA). Deuterated $\mathrm{D}_{2} \mathrm{O}$ $(99.96 \%)$ and DMSO- $d_{6}(99.96 \%)$ ampules were obtained from Cambridge Isotopes Labs (Tewksbury, MA). All reagents and chemicals were used as received unless otherwise specified.

Synthesis of VA-MDO Latex. The fabrication of VM-6 is given as a representative example. The synthesis was carried out using a $1 \mathrm{~L}$, 4-neck round bottom flask outfitted with a condenser, overhead stirrer, thermocouple, and pH probe. Deionized water (285.0 g) was added to the flask, and the contents of the reactor were stirred at $150 \mathrm{rpm}$ and heated to $40{ }^{\circ} \mathrm{C}$ under a nitrogen atmosphere. In a separate vessel, a monomer mixture containing VA (173.0 g) and MDO (43.9 g) was prepared. In a second separate vessel, an aqueous cofeed containing deionized water (46.2 g), 
Na-AMPS solution (1.4 g), TERGITOL 15-S-40 (1.5 g), and SLES (6.2 g) was prepared. Separately, solutions of (i) $70 \mathrm{wt} \% t$-BHP $(0.58 \mathrm{~g})$ and APS (1.38 g) in $37.0 \mathrm{~g}$ water and (ii) Bruggolite FF6 M (2.62 g) in $37.6 \mathrm{~g}$ water were prepared and loaded into plastic syringes. At 40 ${ }^{\circ} \mathrm{C}$, iron (II) sulfate heptahydrate (16.2 $\mathrm{g}, 0.15 \mathrm{wt} \%$ in water), EDTA (3.45 g, $1.0 \mathrm{wt} \%$ in water), and Fes-32 (16.4 g, $31 \mathrm{wt} \%$ in water) were added to the reactor with rinsing (34.4 g water). The $\mathrm{pH}$ of the reactor contents was measured and adjusted to $\mathrm{pH} 8.0$ using ammonium hydroxide. The reactor was held for 1 min and feeding of the redox initiator package $t$-BHP/APS/FF6 M was started at a rate of $0.57 \mathrm{~g} / \mathrm{min}$. After $1 \mathrm{~min}$, the monomer mixture and aqueous cofeed were fed simultaneously into the reactor at a rate of $3.6 \mathrm{~g} / \mathrm{min}$ and $0.92 \mathrm{~g} / \mathrm{min}$, respectively, at a temperature of $39-41{ }^{\circ} \mathrm{C}$. The monomer mixture and aqueous cofeed were fed over $60 \mathrm{~min}$, and the redox initiator package was fed over 70 min total (i.e., the redox package feed continued for 10 min after the monomer mixture feed was complete). Throughout the process, the reactor was maintained at $\mathrm{pH}$ 7.8-8.2 by the addition of small amounts of ammonium hydroxide. The reactor was held for an additional $15 \mathrm{~min}$ at $40{ }^{\circ} \mathrm{C}$ and then cooled to room temperature. The contents of the reactor were adjusted to $\mathrm{pH} 7.0$ using acetic acid and then filtered through a 100 mesh stainless steel filter (pore size $=149 \mu \mathrm{m}$ ) to give VM-6. The final latex had a solids content of $31.6 \mathrm{wt} \%$ (as determined by allowing $\sim 0.5 \mathrm{~g}$ of wet latex to dry overnight at room temperature). Other latex samples were prepared using an analogous process. To adjust the composition, the masses of VA and MDO in the monomer mixture, and the process conditions, were modified as follows. V-1 and V-2: 216.8 g VA only at pH 6.0 and 8.0, respectively; VM-1, VM-2, VM-3, and VM-4: $206.0 \mathrm{~g}$ VA and 10.9 $\mathrm{g} \mathrm{MDO}$ at $\mathrm{pH}$ 6.0, 8.0, 5.0, and 10.0, respectively; VM-5: $184.0 \mathrm{~g}$ VA and $32.9 \mathrm{~g} \mathrm{MDO}$ at $\mathrm{pH}$ 8.0. 
Hydrolysis of MDO. A sample of MDO (40 mg) was weighed into a glass vial and dissolved in DMSO- $d_{6}(800 \mu \mathrm{L}) . \mathrm{D}_{2} \mathrm{O}(80 \mu \mathrm{L})$ was added to the sample to give a clear, colorless solution, with an approximate ratio of $10 \mathrm{~mol}_{2} \mathrm{O}: 1 \mathrm{~mol} \mathrm{MDO}$. The sample was immediately transferred to an NMR tube and spectra were acquired over time, at pre-determined time points. Additional samples were prepared to give approximate ratios of $100 \mathrm{~mol} \mathrm{D}_{2} \mathrm{O}: 1 \mathrm{~mol} \mathrm{MDO}(20 \mathrm{mg} \mathrm{MDO}, 400 \mu \mathrm{L}$ DMSO- $d_{6}, 400 \mu \mathrm{L} \mathrm{D} \mathrm{D}_{2} \mathrm{O}$ ) and $1000 \mathrm{~mol} \mathrm{D}_{2} \mathrm{O}: 1 \mathrm{~mol} \mathrm{MDO}\left(10 \mathrm{mg}\right.$ MDO, $200 \mu \mathrm{L}$ DMSO- $d_{6}, 2000$ $\mu \mathrm{L} \mathrm{D}_{2} \mathrm{O}$ ). Note that the concentration of MDO was not held constant in these experiments; the DMSO- $d_{6}: \mathrm{D}_{2} \mathrm{O}$ ratio was adjusted to ensure solubility of MDO. All samples were prepared and analyzed in duplicate.

Hydrolysis of VA-MDO Latex. A known mass of latex ( 3.0 g, 50\% solids) was combined with ethanol $(\sim 10 \mathrm{~mL})$ and solid $\mathrm{KOH}$ pellets $(\sim 0.45 \mathrm{~g})$ in a Teflon cup nested within a stainless-steel Parr bomb reactor (Model 276AC-T304, Parr Instruments, Moline, Il). The reactors were sealed and placed in an oven at $150^{\circ} \mathrm{C}$ for $24 \mathrm{hr}$, and then cooled to room temperature. In the case of $\mathbf{V}$ 2, a solid brown mass was observed on the bottom of the Parr bomb cup together with a clear, brown liquid supernatant. In the case of VM-6, a clear brown liquid phase only was observed in the Parr bomb cup. In both cases, the entire contents of the Parr bomb reactor was transferred to separate glass vials and the samples were dried under reduced pressure. The resulting polymer solids were then placed in a vacuum oven at $50{ }^{\circ} \mathrm{C}$ overnight to yield off-white solids for both $\mathbf{V}$ 2 and VM-6. A known mass of each sample $(\sim 250 \mathrm{mg})$ was then weighed into a glass vial and 5 $\mathrm{mL}$ of deionized water was added. The samples were heated to $\sim 60^{\circ} \mathrm{C}$ with stirring for $1 \mathrm{hr}$ to give clear solutions. Each sample solution was then transferred to a Spectra/Por G2 Dialysis Device 
$(\mathrm{MWCO}=100-500 \mathrm{Da})$ and dialyzed against water for 3 days. The samples were then freeze-dried to remove water and yield off-white powders.

NMR Spectroscopy on VA-MDO Latex. NMR studies were performed using a Bruker Avance III HD 500 spectrometer equipped with a 5 mm Prodigy BBO CryoProbe (Billerica, MA). Samples were prepared by drying $\sim 0.5 \mathrm{~g}$ of latex in an aluminum pan overnight, prior to dissolution in $\mathrm{CDCl}_{3}$. Hydrolyzed latex samples were prepared by dissolution in DMSO- $d_{6} .1 \mathrm{D}{ }^{1} \mathrm{H}$ spectra were acquired with a pulse repetition delay of $10 \mathrm{~s}$, and $1 \mathrm{D}{ }^{1} \mathrm{H}$ diffusion edited spectra were acquired using the pulse program ledbpgp2s1d with a pulse repetition delay of $10 \mathrm{~s}$ and $\mathrm{P} 30=2000 \mu \mathrm{s}$ to suppress the signal of rapidly diffusing small molecules. In all cases, chemical shifts are reported relative to the residual solvent protons of $\mathrm{CDCl}_{3}\left(\delta^{1} \mathrm{H}, 7.26 \mathrm{ppm} ;{ }^{13} \mathrm{C}, 77.16 \mathrm{ppm}\right)$ or DMSO- $d_{6}(\delta$ $\left.{ }^{1} \mathrm{H}, 2.50 \mathrm{ppm} ;{ }^{13} \mathrm{C}, 39.52 \mathrm{ppm}\right)$.

Dynamic Light Scattering (DLS). DLS was performed using a Malvern Zetasizer Nano ZSP (Malvern, UK). The method assumed a refractive index of 1.479, and particle size is reported as the z-average particle size diameter, from an average of 3 runs of 10 scans.

Differential Scanning Calorimetry (DSC). DSC was performed using a DSC Q2000 differential scanning calorimeter (TA Instruments) over a temperature range of $\mathrm{T}=-90$ to $150{ }^{\circ} \mathrm{C}$ at a heating rate of $10^{\circ} \mathrm{C} / \mathrm{min}$ under a nitrogen atmosphere. The thermal history of each sample was erased in the first cycle by cooling to $-90^{\circ} \mathrm{C}$, followed by heating to $150^{\circ} \mathrm{C}$, and then cooling to $-90^{\circ} \mathrm{C}$. All thermal transitions were assigned from the second heating cycle. 
Attenuated Total Reflectance IR Spectroscopy (ATR IR). Attenuated total reflectance (ATR) IR measurements were obtained using a Nicolet 380 FTIR spectrometer outfitted with an ATR stage. Dried samples were directly deposited onto the ATR stage. Spectra were collected at a resolution of $4 \mathrm{~cm}^{-1}$ and are presented as an average of 32 scans over the range of $450-4000 \mathrm{~cm}^{-1}$. Data were analyzed using OMNIC Software (version 9, Thermo Fisher Scientific Inc, US).

Headspace Gas Chromatography. Headspace gas chromatography for the determination of residual VA in latex samples was performed using a Agilent 6890N gas chromatograph equipped with a Restek RX-200 30 m x 0.32 mm (i.d.) x $1.0 \mu \mathrm{m}$ df column, single split/spitless injector, flame ionization detector (FID), and an Agilent 7697A headspace autosampler. Samples were prepared for analysis by directly weighing a known mass of undiluted latex into a headspace vial containing a known mass of ethylene glycol diethyl ether internal standard (5000 pppm in deionized water). The carrier gas was ultrahigh purity helium, the make-up gas was $\mathrm{N}_{2}$, and the fuel gases were $\mathrm{H}_{2} /$ air. The instrument operated at a column head pressure of 9.5 psi, column flow rate of $2.1 \mathrm{~mL} / \mathrm{min}$, make-up flow rate of $20 \mathrm{~mL} / \mathrm{min}$, hydrogen flow rate (FID) of $40 \mathrm{~mL} / \mathrm{min}$, and air flow rate (FID) of $400 \mathrm{~mL} / \mathrm{min}$. The temperature program parameters were as follows: $40{ }^{\circ} \mathrm{C}$ initial temperature, 3 min equilibration time, $20{ }^{\circ} \mathrm{C} / \mathrm{min}$ to $245^{\circ} \mathrm{C}$ ramp, 5 min final hold time, cool to $40{ }^{\circ} \mathrm{C}$, with an inlet temperature of $180^{\circ} \mathrm{C}$. The headspace parameters were as follows: $10 \mathrm{~min}$ vial equilibration, $0.1 \mathrm{~min}$ vial pressurization, $0.3 \mathrm{~min}$ injection, $0.1 \mathrm{~min}$ loop equilibration, 0.05 min loop fill, with a loop temperature of $140{ }^{\circ} \mathrm{C}$, oven temperature of $130{ }^{\circ} \mathrm{C}$, and transfer line temperature of $180{ }^{\circ} \mathrm{C}$. The instrument was calibrated from 10000 to 5 ppm using high purity VA (99\%) standards (obtained from Sigma Aldrich, Milwaukee, WI). 
High Performance Liquid Chromatography (HPLC) Analysis of Acetic Acid. HPLC analysis was performed using an Agilent 1100 Series HPLC equipped with a Phenomenex Rezex ROA Organic Acid H+ 240 x 4.6 mm column ( $8 \mu \mathrm{m}$ particle size, $8 \%$ cross-linked sulfonated styrenedivinylbenzene), Phenomenex Carbo-H4 column guard, and UV detector operating at a wavelength of $210 \mathrm{~nm}$. Latex samples for analysis were centrifuged at $100 \mathrm{~K} \mathrm{rpm}$ for $15 \mathrm{~min}$ and the supernatant was then filtered through a $0.45 \mu \mathrm{m}$ PVDF syringe filter. The sample injection volume was $5 \mu \mathrm{L}$ and separations were performed with $2.5 \mathrm{mM}$ phosphoric acid at a flow rate of $0.4 \mathrm{~mL} / \mathrm{min}$ and a column temperature of $35^{\circ} \mathrm{C}$. The instrument was externally calibrated from 50 to $10000 \mathrm{ppm}$ using acetic acid.

Gel Permeation Chromatography (GPC). Latex samples were prepared for GPC by dilution in $50 \mathrm{mM} \mathrm{LiBr}$ in $N, N$-dimethylacetamide at a concentration of approximately $3 \mathrm{mg} / \mathrm{mL}$ (based on polymer solids), and then heated at $90{ }^{\circ} \mathrm{C}$ with stirring for $2 \mathrm{hr}$. Samples were cooled to room temperature and then filtered through a $0.45 \mu \mathrm{m}$ PTFE syringe filter. GPC separations were performed on a Waters Acquity Advanced Polymer Chromatography (APC) system equipped with a pump, column thermostat, autosampler, and refractive index detector operating at a wavelength of $254 \mathrm{~nm}$. The instrument was equipped with two PLgel columns ( $300 \times 7.5 \mathrm{~mm}$ i.d.), packed with Mixed C (particle size $=5 \mu \mathrm{m})$ and Mixed E (particle size $=3 \mu \mathrm{m})$ crosslinked polystyrenedivinylbenzene beads, respectively. The column oven and the refractive index detector operated at $40{ }^{\circ} \mathrm{C}$. The sample injection volume was $100 \mu \mathrm{L}$ and separations were performed with $50 \mathrm{mM}$ $\mathrm{LiBr}$ in $N, N$-dimethylacetamide as the eluent at a flow rate of $0.5 \mathrm{~mL} / \mathrm{min}$. The instrument was calibrated with twelve narrow-dispersity poly(methyl methacrylate) standards from 540 2,210,000 Da (Agilent, Santa Barbara, CA). Data acquisition was performed using the Waters 
Empower software package (version 3.0; Milford, MA). Data analysis was carried out using the Cirrus software package (version 3.3; Polymer Laboratories, a division of Agilent, Church Stretton, UK).

Matrix-Assisted Laser Desorption Ionization (MALDI) Mass Spectrometry: MALDI time-offlight (MALDI-ToF) mass spectrometry experiments were performed using a Bruker UltrafleXtreme instrument, over the mass range $400-5000 \mathrm{Da}$, operating at $40 \%$ laser power. Spectra are reported as an average of 5000 laser pulses. Samples were prepared for analysis using the dried droplet technique. A matrix solution was prepared by dissolving $20 \mathrm{mg}$ of 2,5dihydroxybenzoic acid (DHB) in $1 \mathrm{~mL}$ of water:acetonitrile (70:30 vol/vol). A solution of $\mathrm{NaI}(2$ $\mu \mathrm{L}, 0.5 \mathrm{mg} / \mathrm{mL}$ in methanol) was added to the matrix solution as a cationization aid. Separately, a sample solution was prepared by dissolving $10 \mathrm{mg}$ of freeze-dried polymer in $1 \mathrm{~mL}$ of MilliQ water. The matrix and sample solutions were mixed at a 10:1 ratio ( $\mathrm{vol} / \mathrm{vol})$ and vortexed vigorously for $10 \mathrm{~s}$. The resulting solution was applied to the target plate in $1 \mu \mathrm{L}$ aliquots and allowed to air dry prior to MALDI-MS analysis.

Film Hydrolysis Studies. Using a micropipet, aliquots of V-2 and VM-6 (330 $\mu \mathrm{L})$ were drop-cast into pre-weighed, circular aluminum pans (Andwin Scientific; $13 \times 3.5 \mathrm{~mm}, 0.35 \mathrm{~mL}$ total capacity) and then dried at room temperature overnight. The samples were then placed in a vacuum oven for 5 days at $25-30{ }^{\circ} \mathrm{C}$ and dried to constant mass, as determined using an analytical balance. 20 identical film samples were prepared for each latex, V-2 and VM-6 (40 samples total). The average dry film thickness was $\sim 2.5 \mathrm{~mm}$, as determined using a micrometer. Each film sample was then placed into a separate plastic centrifuge tube containing $50 \mathrm{~mL}$ of PBS buffer at $\mathrm{pH} 7.4$ and 
all samples were agitated on a shaker plate. Duplicate samples were removed at pre-determined time points for analysis. Samples were rinsed briefly with acetone, and then copiously with deionized water, and dried on high vacuum ( 20-30 mTorr) overnight at room temperature. After 50 days of incubation, the remaining samples were transferred from PBS to $50 \mathrm{~mL}$ of bicarbonate buffer at $\mathrm{pH}$ 10.0; these samples were removed at pre-determined time points as before. All dried samples were weighed using an analytical balance, and mass loss was recorded. Randomly selected samples were placed under high vacuum for additional time periods to confirm that the drying protocol described above yielded a constant final mass.

Paper Coatings Testing. Latex samples $(\sim 100 \mathrm{~g})$ were prepared by adjusting to $\mathrm{pH} 9.5$ with ammonium hydroxide, and then adding ASE-60 (2-4 g) dropwise with stirring to achieve a Brookfield viscosity of approximately $2000 \mathrm{cP}$ at 20 and $600 \mathrm{cP}$ at $100 \mathrm{rpm}$. These sample formulations at approximately 30\% solids were applied to NewPage Glazewrap free sheet paper (base weight $=60 \mathrm{~g} / \mathrm{m}^{2}$, Verso Corp., Memphis, TN) using an RK K202 Control Coater automated coater (RK Print Coat Instruments, Litlington, UK) equipped with a KCC202 wire-wound rod (US $\operatorname{rod} \# 9,0.00075 ”$ diameter, $18 \mu \mathrm{m}$ spacing, obtained from Testing Machines Inc., New Castle, DE) targeting a dry coat weight of $10 \mathrm{~g} / \mathrm{m}^{2}$. Coated samples were placed in an oven at $80{ }^{\circ} \mathrm{C}$ for $2 \mathrm{~min}$, and final coat weights were determined by cutting out a fixed area, determining the mass, and subtracting the known mass of the paper substrate. Coat weights are reported as an average of at least six areas. Coated paper samples were conditioned in a controlled temperature room for $4 \mathrm{hr}$ prior to testing. Samples were tested according to the so-called 'Kit test', Technical Association of the Pulp and Paper Industry (TAPPI) Method T $559 \mathrm{~cm}-12$, "Grease resistance test for paper and paperboard" (test materials were obtained from 3M Corp., Minneapolis, MN). Twelve test 
solutions consisting of mixtures of castor oil, toluene, and heptane were prepared as prescribed by the method. Coated paper samples were folded in half and creased manually. The test solutions were applied dropwise to the creased sample area at room temperature. After $15 \mathrm{sec}$, the samples were visually observed, and evidence of solvent breakthrough or resistance to breakthrough was recorded. The test solutions were wiped from the sample, and samples were again observed. Any discoloration or change in appearance (e.g., evidence of residual oil and penetration into the coating) in response to a Kit solution was recorded as a fail for that test solution. As described by the method, the final 'Kit score' reported indicates the total number of test solutions for which a given sample passed the test, with higher scores indicating greater resistance to fouling. 


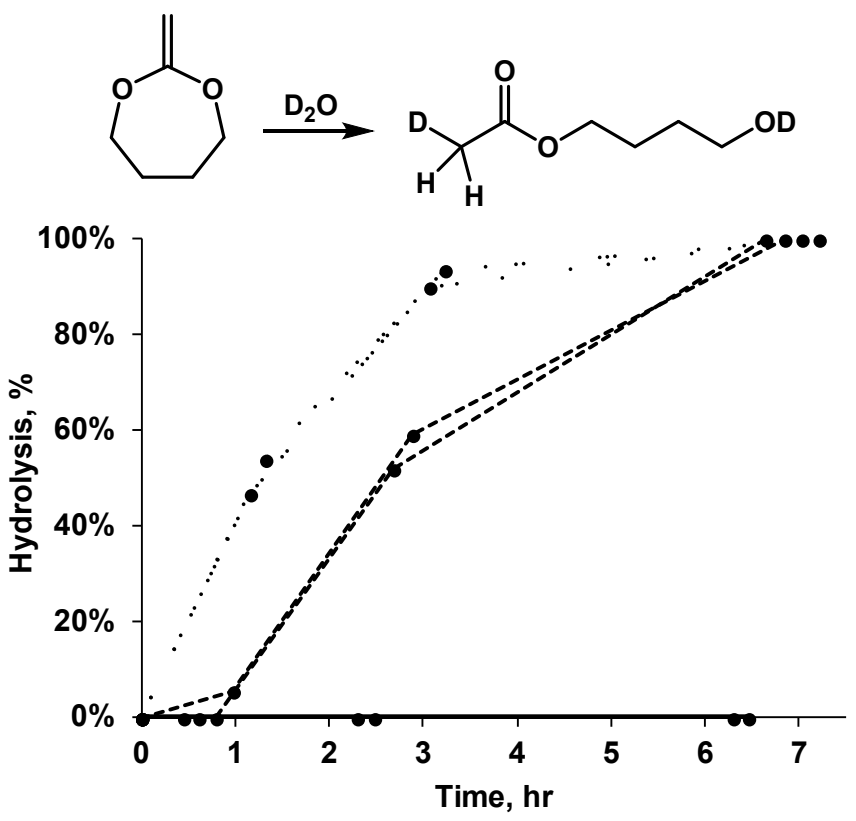

Figure S1. Hydrolysis of MDO in DMSO- $d_{6} / \mathrm{D}_{2} \mathrm{O}$ solutions, as determined by ${ }^{1} \mathrm{H}$ NMR spectroscopy at room temperature over time. Samples were prepared in duplicate at 10:1 (solid), 100:1 (dashed), and 1000:1 (dotted) $\mathrm{D}_{2} \mathrm{O}: \mathrm{MDO}$, on a mol basis. Percent hydrolysis was determined by the following equation: Hydrolysis, $\%=\left(I_{\mathrm{CH} 2 \text {,ester }} / 2 \mathrm{H}\right) /\left[\left(I_{\mathrm{CH} 2 \text {,ester }} / 2 \mathrm{H}\right)+\left(I_{-\mathrm{CH} 2-\mathrm{CH} 2-\mathrm{MDO}} / 4 \mathrm{H}\right)\right] \times 100 \%$, where $I_{\mathrm{CH} 2 \text {,ester }}$ is the integration value of the ester protons $(2 \mathrm{H})$ in the hydrolysis product 4-hydroxybutyl acetate at $4.06 \mathrm{ppm}$, and $I_{-}{ }_{-}{ }_{2-C H 2-, M D O}$ is integration value of the aliphatic methylene protons $(4 \mathrm{H})$ in MDO at $3.83 \mathrm{ppm}$. 

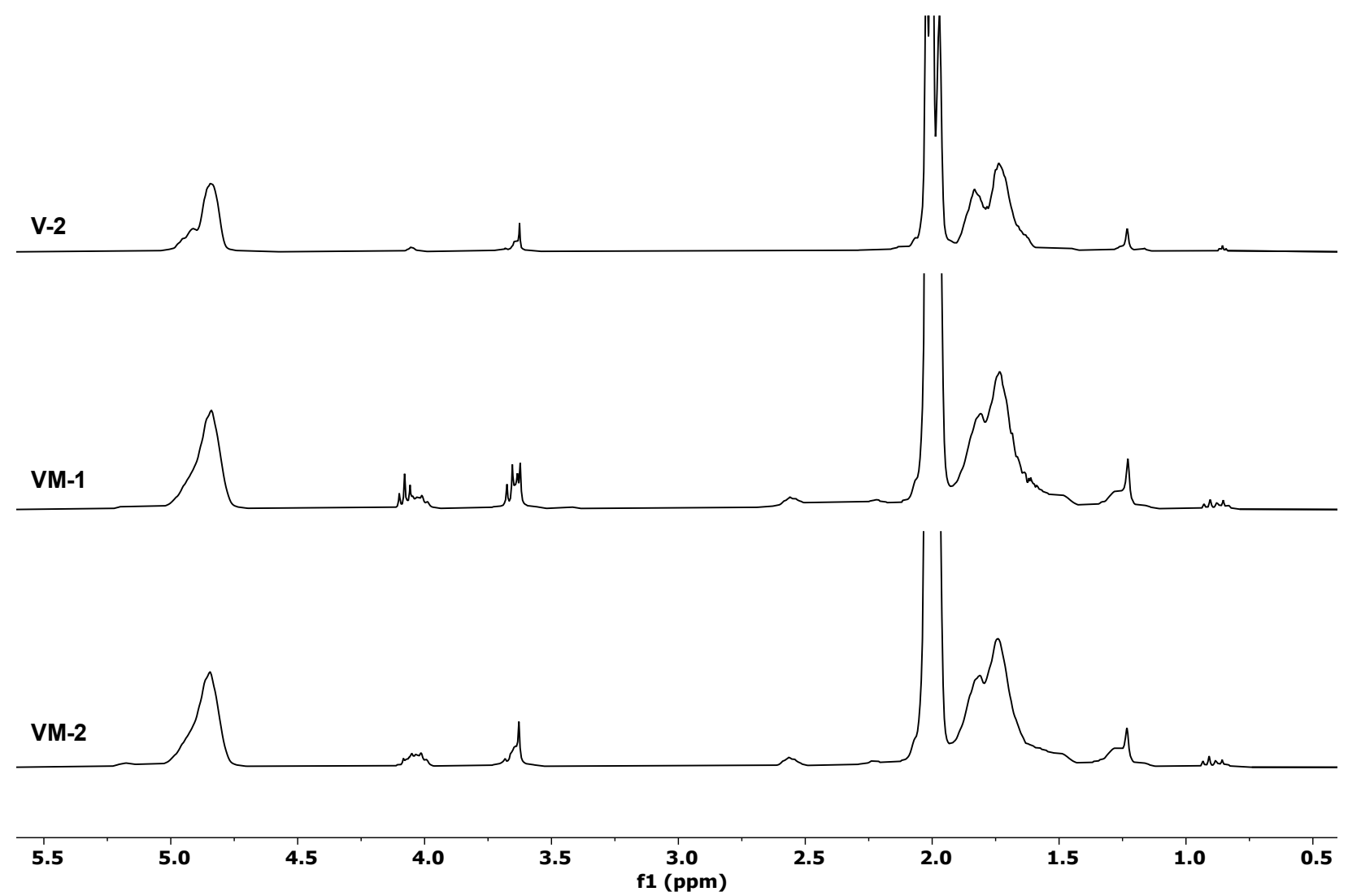

Figure S2. ${ }^{1} \mathrm{H}$ NMR spectra for V-2, VM-1, and VM-2 in $\mathrm{CDCl}_{3}$, obtained after drying the latex samples to remove water. Key peak assignments are made in Figure $\mathbf{1}$ of the main text and further NMR analysis of VM latex is given in Figure S3, S4, and S6. 

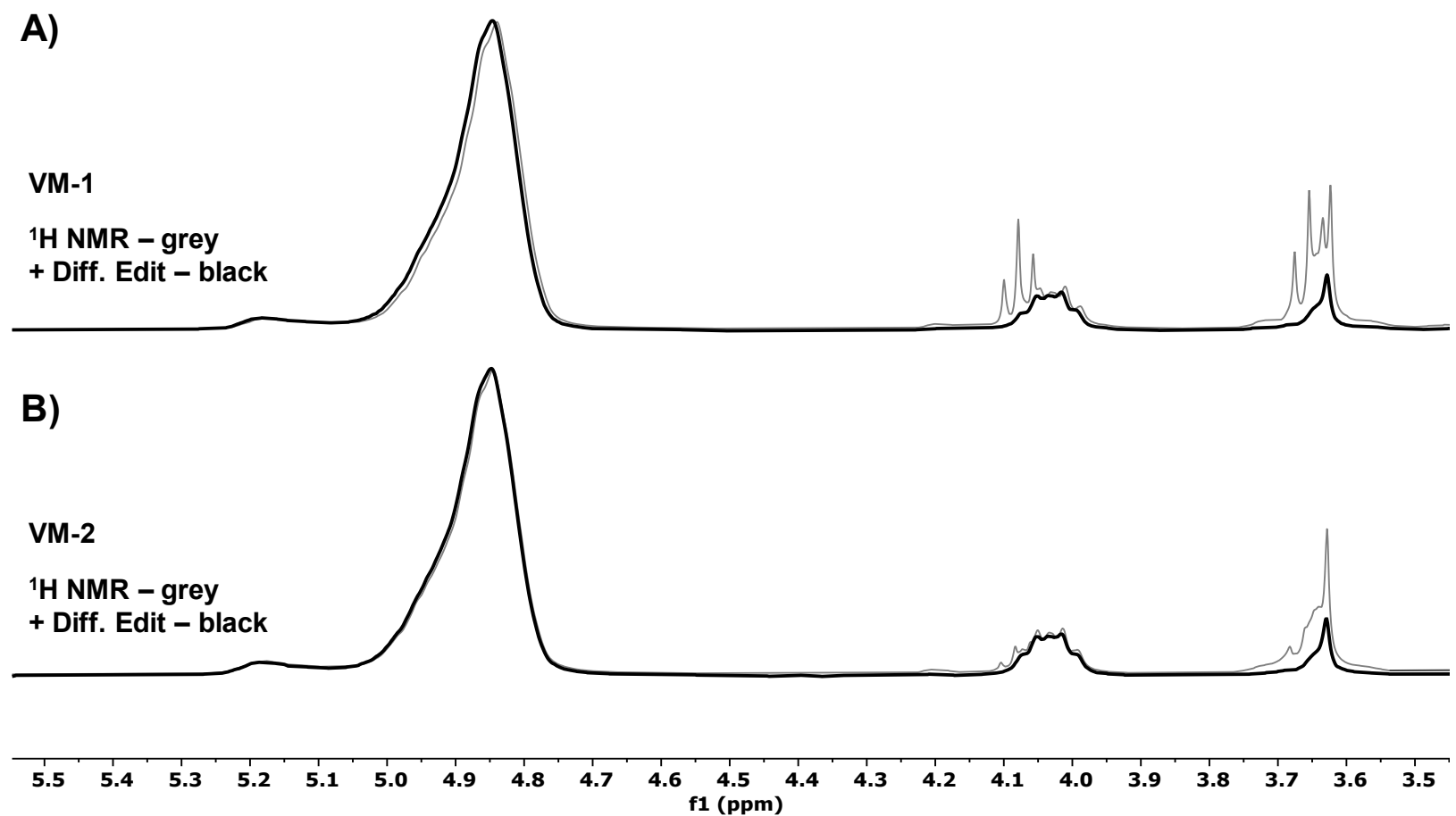

Figure S3. ${ }^{1} \mathrm{H}$ NMR (grey) and corresponding diffusion-edited ${ }^{1} \mathrm{H}$ NMR spectra (black) for (A) VM-1 and (B) VM-2 in $\mathrm{CDCl}_{3}$. The spectral range is shown from 3.5-5.5 ppm, and the peaks used to determine the polymer composition by integration in the diffusion-edited spectra are visible [VA backbone $(1 \mathrm{H},-\mathrm{CH}-)$ and MDO polymerized ester $\left.\left(2 \mathrm{H},-\mathrm{C}(=\mathrm{O})-\mathrm{O}-\mathrm{CH}_{2}-\right)\right]$. Composition data for all polymers is summarized in Table 1 of the main text. The spectra are overlaid to show that the application of a diffusion filter $(\mathrm{P} 30=$ $2000 \mu \mathrm{s}$ ) does not cause a loss in the area of the polymer signals of interest (i.e., only the small molecule 4hydroxybutyl acetate tends to diffuse out of the data). Note that the peak at $\sim 3.64 \mathrm{ppm}$ that persists in the diffusion-edited spectra is due to surfactant adsorbed to polymer $\left(2 \mathrm{H},-\mathrm{C}_{2^{-}}\right.$, ethylene oxide units in SLES). 


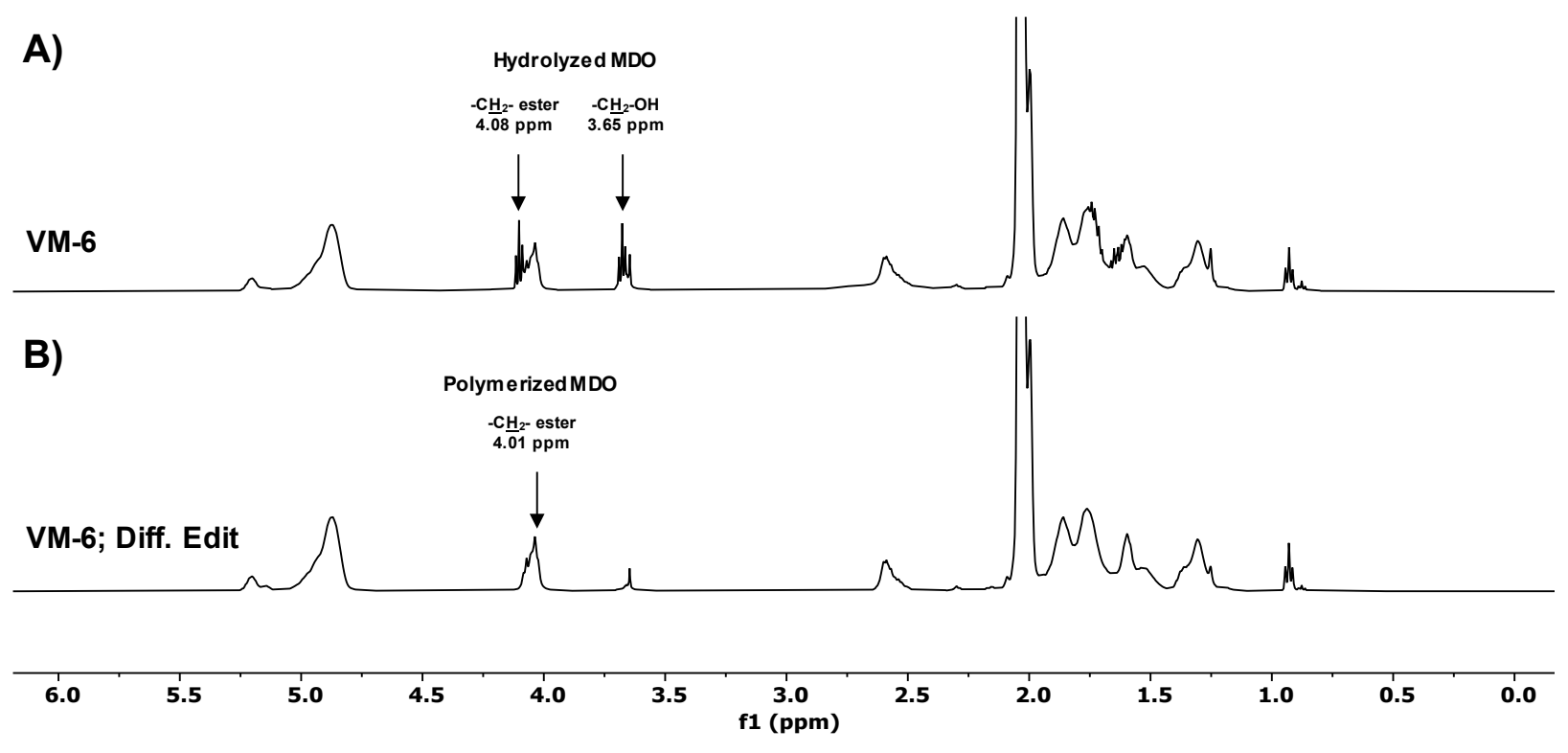

Figure S4. (A) ${ }^{1} \mathrm{H}$ NMR and (B) corresponding diffusion-edited ${ }^{1} \mathrm{H}$ NMR spectra for VM-6 in $\mathrm{CDCl}_{3}$. Select peak assignment are highlight directly on the spectra. See also Figure S3 for additional data.

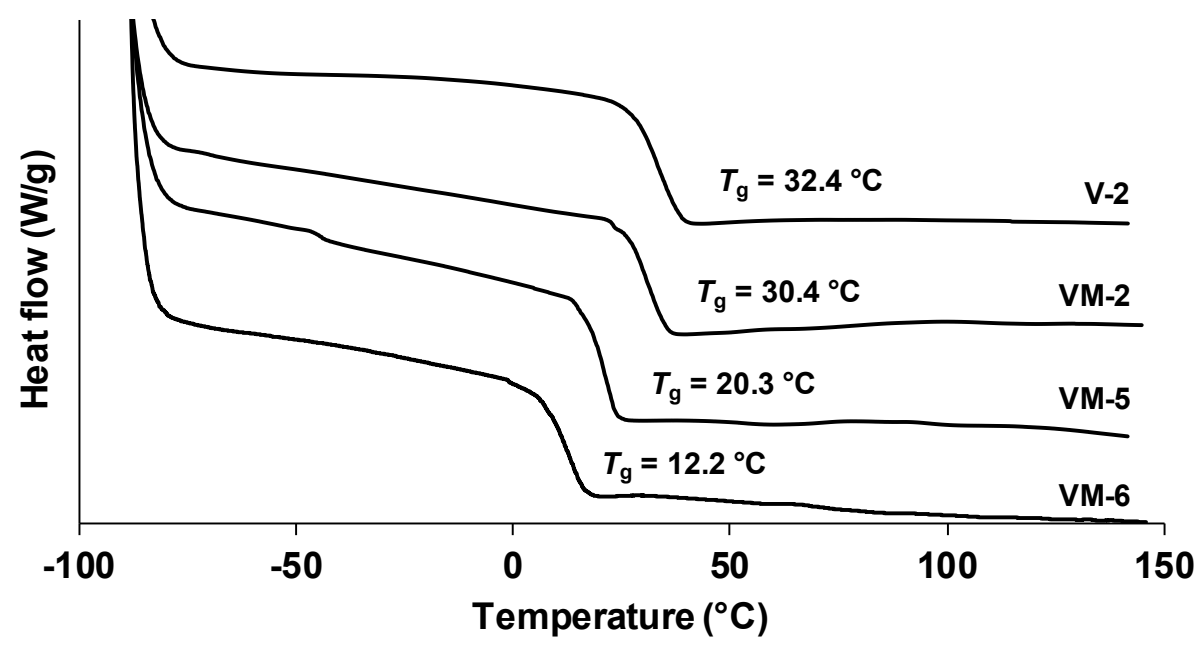

Figure S5. DSC data for select samples as described in the main text. All $T_{\mathrm{g}}$ assignments were made from the second heating cycle. 

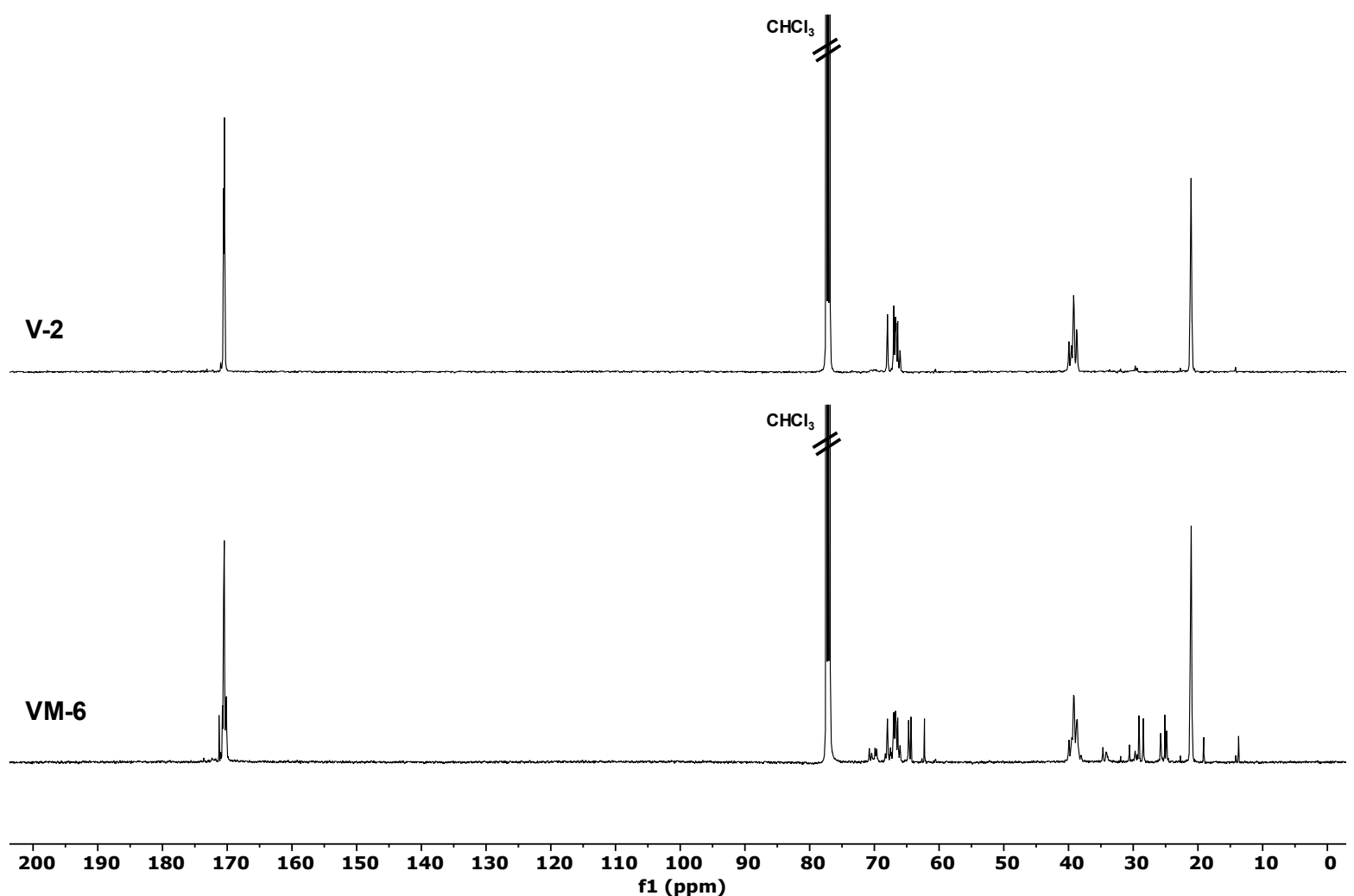

Figure S6. Quantitave ${ }^{13} \mathrm{C}$ inverse-gated NMR spectra for V-2 and VM-6 in $\mathrm{CDCl}_{3}$. The absence of a peak near $\sim 100 \mathrm{ppm}$ strongly suggests that polymerization of the ring-closed form of MDO (1,2-addition or propagation) does not occur under the conditions reported here, in good agreement with past results on the copolymerization of VA and MDO in organic solvents. (See Agarwal, S. et al., Polym. J. 2009, 41, 650660 and Undin, J. et al., Polym. Chem. 2012, 3, 1260-1266). 


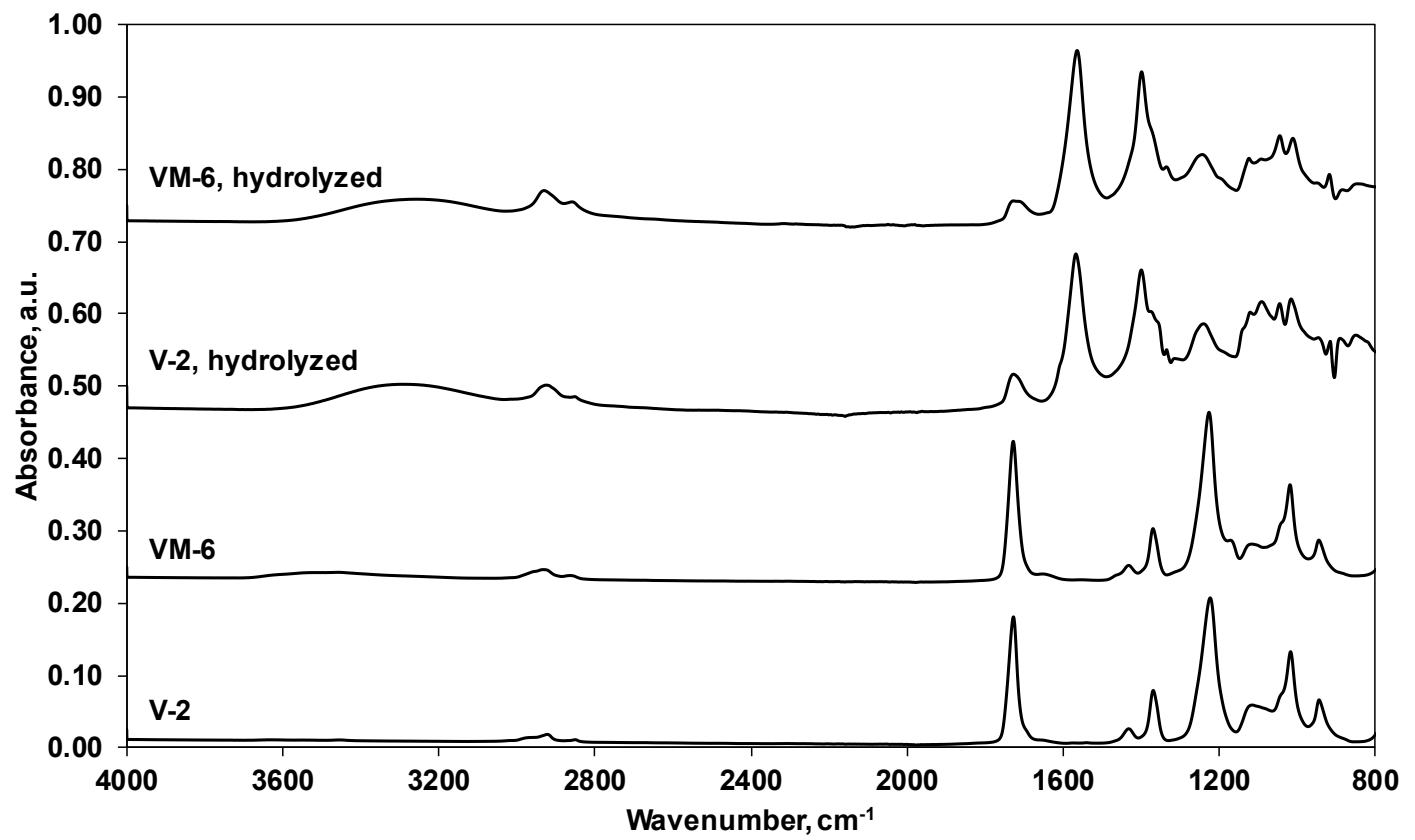

Figure S7. Attenuated total reflectance (ATR) IR spectra for V-2, VM-6, and the corresponding hydrolyzed samples as indicated on the figure. A weak peak at $\sim 1160 \mathrm{~cm}^{-1}$ in VM-6 may correspond to the ether bond (C-O-C) of polymerized MDO; this peak is absent in the spectra of V-2. The VA acetate side-chain carbonyl peak at $\sim 1730 \mathrm{~cm}^{-1}$, in both samples, is still visible after hydrolysis, suggesting incomplete conversion of this group (see also ${ }^{1} \mathrm{H}$ NMR spectra in Figure S8). The hydrolyed samples were not purified by dialysis prior to obtaining the data shown in the figure, thus, the peak at $\sim 1730 \mathrm{~cm}^{-1}$ may also correspond to residual acetic acid, and in addition, the peak at $\sim 1560 \mathrm{~cm}^{-1}$ may indicate the presence of sodium acetate. 


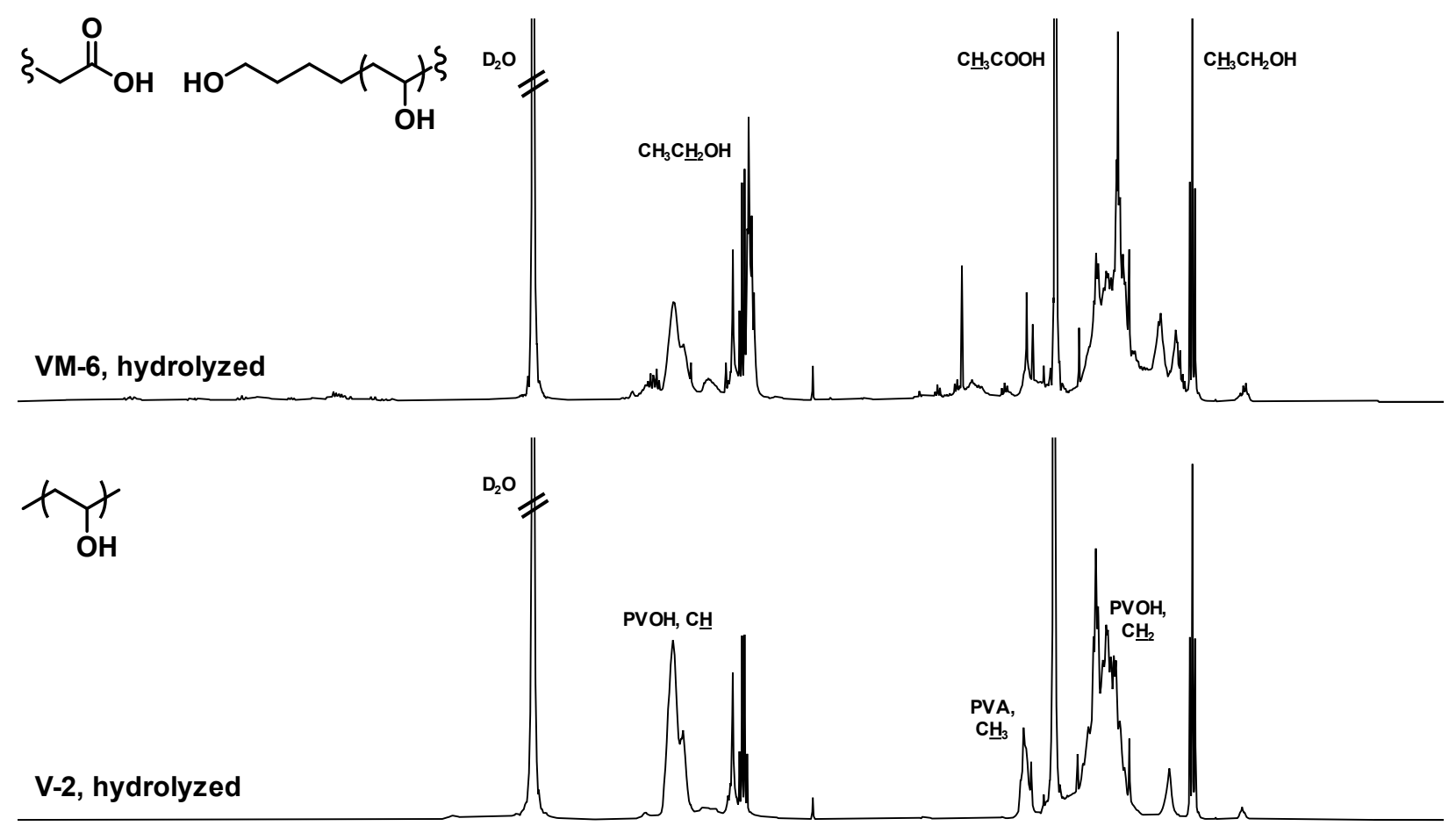

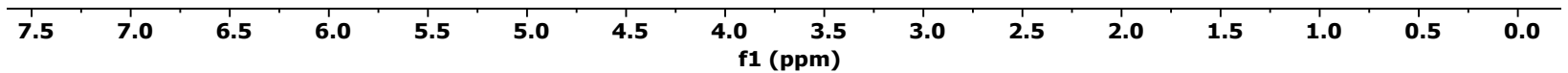

Figure S8. ${ }^{1} \mathrm{H}$ NMR spectra for V-2 and VM-6 after hydrolysis in DMSO- $d_{6}$. The samples were dried under high vacuum but not dialyzed prior to analysis. The data show that hydrolysis of the VA acetate side-chains was incomplete under these conditions, as evidenced by a peak at $2.08 \mathrm{ppm}$ in both samples corresponding the methyl group of intact acetate side-chains (see also ATR IR data in Figure S7). Peaks corresponding to PVOH at $4.02 \mathrm{ppm}$ (backbone - $\underline{\mathrm{CH}}-$ ) and from 1.48-1.77 ppm (backbone, $-\mathrm{C}_{2}{ }^{-}$) are observed in both samples. Peaks indicating the presence of residual ethanol are observed at $1.16 \mathrm{ppm}\left(t, \mathrm{C}_{3}\right)$ and $3.54 \mathrm{ppm}$ $\left(q, \underline{\mathrm{CH}}_{2}\right)$. 